\title{
Does the weather make us sad? Meteorological determinants of mood and depression in the general population
}

Citation for published version (APA):

Huibers, M. J. H., de Graaf, L. E., Peeters, F. P. M. L., \& Arntz, A. R. (2010). Does the weather make us sad? Meteorological determinants of mood and depression in the general population. Psychiatry Research, 180(2-3), 143-146. https://doi.org/10.1016/j.psychres.2009.09.016

Document status and date:

Published: 30/12/2010

DOI:

10.1016/j.psychres.2009.09.016

Document Version:

Publisher's PDF, also known as Version of record

Document license:

Taverne

Please check the document version of this publication:

- A submitted manuscript is the version of the article upon submission and before peer-review. There can be important differences between the submitted version and the official published version of record.

People interested in the research are advised to contact the author for the final version of the publication, or visit the DOI to the publisher's website.

- The final author version and the galley proof are versions of the publication after peer review.

- The final published version features the final layout of the paper including the volume, issue and page numbers.

Link to publication

\footnotetext{
General rights rights.

- You may freely distribute the URL identifying the publication in the public portal. please follow below link for the End User Agreement:

www.umlib.nl/taverne-license

Take down policy

If you believe that this document breaches copyright please contact us at:

repository@maastrichtuniversity.nl

providing details and we will investigate your claim.
}

Copyright and moral rights for the publications made accessible in the public portal are retained by the authors and/or other copyright owners and it is a condition of accessing publications that users recognise and abide by the legal requirements associated with these

- Users may download and print one copy of any publication from the public portal for the purpose of private study or research.

- You may not further distribute the material or use it for any profit-making activity or commercial gain

If the publication is distributed under the terms of Article 25fa of the Dutch Copyright Act, indicated by the "Taverne" license above, 


\title{
Does the weather make us sad? Meteorological determinants of mood and depression in the general population
}

\author{
Marcus J.H. Huibers ${ }^{\text {a, }}{ }^{*}$, L. Esther de Graaf ${ }^{a}$, Frenk P.M.L. Peeters ${ }^{b}$, Arnoud Arntz ${ }^{a}$ \\ a Department of Clinical Psychological Science, Maastricht University, The Netherlands \\ ${ }^{\mathrm{b}}$ Department of Psychiatry, University Hospital Maastricht, The Netherlands
}

\section{A R T I C L E I N F O}

Article history:

Received 30 April 2009

Received in revised form 24 September 2009

Accepted 29 September 2009

\section{Keywords:}

Depression

Seasonal prevalence

Meteorological factors

General population study

\begin{abstract}
A B S T R A C T
It is a common and well-spread belief that people feel more depressed when the weather is bad. However, whether meteorological factors such as temperature, sunshine and rainfall can actually account for variations in the prevalence of depression in the general population has yet to be investigated. We aimed to assess the influence of weather conditions on the seasonal variation of depression observed in the general population. We used data from a large-scale depression-screening programme in the south of the Netherlands. Seasonal prevalence of DSM-IV classified major depression and sad mood in a sample of 14,478 participants from the general population was calculated, and linked to mean daily temperature, duration of sunshine and duration of rainfall in logistic regression analyses. The prevalence of major depression and sad mood showed seasonal variation, with peaks in the summer and fall. Weather conditions were not associated with mood, and did not explain the seasonal variation we found. We conclude that, contrary to popular belief, weather conditions and sad mood or depression do not seem to be associated. Future studies might use daily measures of well-being as outcome.
\end{abstract}

(c) 2009 Elsevier Ireland Ltd. All rights reserved.

\section{Introduction}

The seasonal variation of depressive symptoms has received a considerable amount of attention in recent years. A specific form of seasonality, seasonal affective disorder (SAD) (Rosenthal et al., 1984), also known as winter depression, appears to be relatively common (Magnusson, 2000). Seasonality also seems to be associated with increased suicide counts (e.g. (Page et al., 2007), and depressive symptoms in the general population are reported to vary monthly (Harmatz et al., 2000; Oyane et al., 2008; Stordal et al, 2008), although other studies failed to find seasonality (de Graaf et al., 2005). While a peak prevalence of depression is usually reported during the winter months (Harmatz et al., 2000; Magnusson, 2000; Morken et al., 2002; Murase et al., 1995; Nayyar and Cochrane, 1996; Oyane et al., 2008), other population studies demonstrate symptom peaks during spring (Nayha et al., 1994; Stordal et al., 2008), summer (Ozaki et al., 1995) and fall (Stordal et al., 2008).

But what exactly is it that accounts for the presumed seasonality of depressive symptoms? For obvious reasons, meteorological factors such as temperature, sunshine and rainfall seem good candidates. In fact, it is a common and well-spread belief that people become

\footnotetext{
* Corresponding author. Department of Clinical Psychological Science, Maastricht University, P.O. Box 616, 6200 MD Maastricht, The Netherlands. Tel.: +31 43388 1487; fax: +31433884155 .

E-mail address: m.huibers@maastrichtuniversity.nl (M.J.H. Huibers).
}

'depressed' when the weather is bad, and feel happy when the sun is shining (Watson, 2000).

However, strong empirical evidence for such an association is lacking (for a review, see (Watson, 2000)). An earlier study among 126 SAD patients showed that increases in (hours of) sun time, day length and temperature were associated with lower depression scores, while (hours of) rainfall was not significantly associated (Molin et al., 1996), but these findings cannot be generalized to other populations. Watson reviewed data collected in 478 students, and found that mood was unrelated to (hours of) sunshine and rain (Watson, 2000). Whether meteorological factors can actually account for seasonal variations of depression observed in the general population has yet to be investigated. We aim to do so, and clarify these relations in the present study.

\section{Methods \\ 2.1. Design and participants}

We report data from a large-scale screening programme that we conducted in the south of the Netherlands (latitude $51^{\circ} 15^{\prime} \mathrm{N}$ ) to recruit participants for a depression treatment study. From December 2005 to June 2007, 217,816 individuals (age 18-65) randomly selected from the general population were sent an invitation letter to complete a screening questionnaire via the Internet. Six municipalities cooperated by providing names and addresses of their residents. Every week, a batch of 2000 to 3000 letters was sent out. In total 23,392 individuals responded (response rate $11 \%$ ) over the course of 18 months and completed the large Internet-based screening questionnaire. For the present analysis, we used data collected in the first 12 months, from 1 December 2005 to 1 December 2006, in which 14,478 responders (response rate 11\%) from the general population completed the screening questionnaire on the Internet. 


\subsection{Measures}

2.2.1. Diagnostic Inventory for Depression

The Diagnostic Inventory for Depression (DID) is a 38-item self-report scale designed to measure DSM-IV symptom inclusion criteria for a major depressive episode (Zimmerman et al., 2004). The DID consists of 19 symptom severity items, three symptom frequency items, seven items measuring interference in daily functioning due to depression and nine quality-of-life items. Specified cut-offs to determine the presence or absence of each DSM-IV criterion can be used to diagnose a major depressive disorder. Psychometric properties of the DID are good in terms of internal consistency, test-retest reliability, convergent and discriminant validity, and diagnostic performance (Sheeran and Zimmerman, 2002; Zimmerman et al., 2006).

\subsubsection{Classification of depression status}

Participants were classified as major depressive disorder (MDD) cases if they reported the presence of one of the DSM-IV key symptoms (depressed mood and/or anhedonia) and four or more DSM-IV depressive symptoms, as measured with the DID. Participants were classified as suffering from a sad mood if they responded positively (i.e., a score of 2 or more) on the corresponding item of the DID ("During the past week, have you been feeling sad or depressed?").

\subsubsection{Meteorological factors}

The Royal Dutch Meteorological Institute (KNMI, www.knmi.nl) in the Netherlands provided data on mean daily temperature (in degrees Celsius), daily duration of sunshine (in hours) and daily duration of rainfall (in hours) for every day of the study period in the south of the Netherlands. Data were collected at the regional weather station in Beek, Limburg, between 1 December 2005 and 1 December 2006.

\subsubsection{Meteorological season}

According to the meteorological season calendar, spring begins on March 1, summer on June 1, autumn on September 1 and winter on December 1. Classification of season was based on the date on which the questionnaire was filed out.

\subsubsection{Other variables}

Other variables included age, gender, education and marital status. Educational attainment was classified as high (e.g., university), medium (e.g., vocational training), low (e.g., elementary school).

\subsection{Statistical analysis}

We calculated the seasonal prevalence of major depressive disorder (MDD) and sad mood, and used chi-square tests to test for seasonal variation (based on season), in the total sample and stratified by gender, since many studies have observed large gender differences in depression.

We then used stepwise logistic regression analyses to test whether the meteorological factors temperature, duration of sunshine and duration of rainfall were associated with $\operatorname{MDD}($ yes $=1$, no $=0$ ) and sad $\operatorname{mood}(y e s=1$, no $=0$ ) in the general population, controlling for meteorological season. In a first step, univariate associations were calculated by linking the mood status of responders to the meteorological factors on the day of response. In a second step, all three meteorological factors were entered simultaneously in a multiple logistic regression model, together with meteorological season. We also adjusted for age, gender, education and marital status in a third step, but since this did not alter our findings, we left these factors out of our analyses. All analyses were carried out using SPSS (version 12.0 for Windows).

\section{Results}

\subsection{Demographic characteristics}

In total 14,478 individuals completed our screening questionnaire of the Internet in the first 12 months of the study period. Response rates across the seasons were fairly comparable $(11 \%, 10 \%, 11 \%$ and $12 \%$, for respectively spring, summer, fall and winter). Mean age (S.D.) in the sample was 43.7 years (12.6), and 8208 (56.1\%) of the participants were female. Educational attainment (high, medium, low) was, respectively, $34.9,50.6$, and $14.5 \%$, while $17.6 \%$ was single, $75.4 \%$ had a partner and $7 \%$ was divorced or widowed. We compared these and other demographic variables of our responders to the population in the southern part of the Netherlands (Statistics Netherlands; www. cbs.nl), and found no major discrepancies, suggesting that our sample is representative for the general population in the south. We also investigated the association between response rate and meteorological factors in ancillary linear regression analyses, but found no significant or meaningful findings.
Table 1

Mean (S.D.) temperature, sunshine and rainfall over the seasons.

\begin{tabular}{lcll}
\hline & $\begin{array}{l}\text { Daily temperature, } \\
\text { in degrees Celsius }\end{array}$ & $\begin{array}{l}\text { Daily duration } \\
\text { sunshine, in hours }\end{array}$ & $\begin{array}{l}\text { Daily duration } \\
\text { rainfall, in hours }\end{array}$ \\
\hline Spring & $9.4(5.3)$ & $4.6(3.5)$ & $2.1(2.9)$ \\
Summer & $18.4(4.4)$ & $6.5(4.8)$ & $0.9(1.7)$ \\
Fall & $13.7(4.8)$ & $3.7(3.2)$ & $1.4(2.2)$ \\
Winter & $2.2(3.2)$ & $1.7(2.4)$ & $1.7(2.9)$ \\
\hline
\end{tabular}

\subsection{Seasonal prevalence}

In Table 1, mean temperature, sunshine and rainfall for every season is shown. In Figs. 1 and 2, the seasonal prevalence of major depression and sad mood is displayed. Prevalence of major depression and sad mood differed significantly over the seasons in the total sample and in men and women $(P<0.01)$, except for the prevalence of major depression in women $(P=0.30)$. The peak prevalence of major depression in the total group was observed in the summer (for men: summer; for women: fall), while the peak prevalence of sad mood was observed in the fall (for men: summer; for women: fall). Spring and winter had the lowest prevalence of major depression and sad mood.

\subsection{Meteorological determinants of major depressive disorder and sad mood}

In Tables 2 and 3, results from our logistic regression analyses are displayed. Odds ratios for the univariate association between the meteorological determinants temperature, sunshine and rainfall and the outcome major depression were all estimated at 1 (Table 2), indicating no association whatsoever between the weather and the prevalence of major depression that day. These odds ratios remained unchanged in a multiple regression model, controlling for meteorological season and the other determinants.

Results from our analyses with sad mood as the outcome variable were almost identical (Table 3 ).

In ancillary analyses (results not shown), we associated a variety of meteorological determinants (mean daily scores of temperature, sunshine and rainfall; mean weekly scores of temperature, sunshine and rainfall; mean monthly scores of temperature, sunshine and rainfall (in accordance with the sad mood item of the DID); mean quarterly scores of temperature, sunshine and rainfall; mean monthly and quarterly scores of temperature, sunshine and rainfall preceding the date the screening questionnaire was completed, in different time lags of 1, 3 and 6 months) and associated them with a variety of outcomes (MDD status; sad mood status; mean severity of depression according to the DID), in the total sample and stratified by gender. We also investigated interaction effects of weather conditions and season

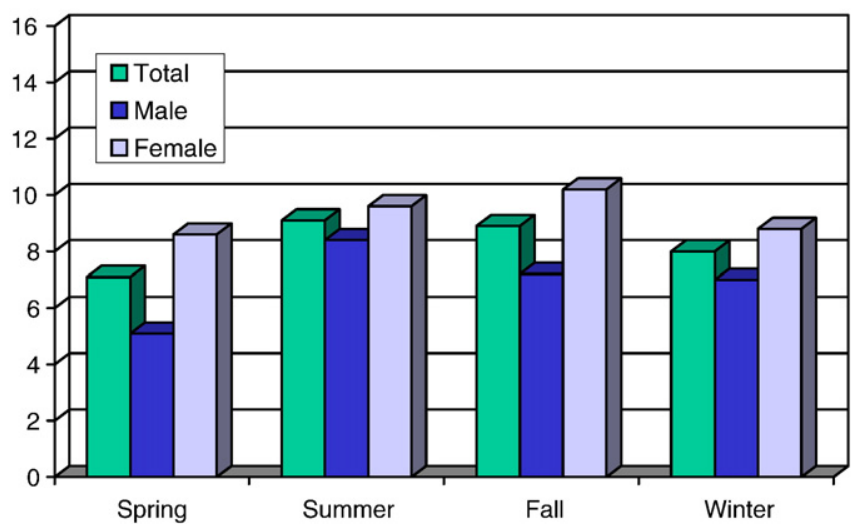

Fig. 1. Prevalence of major depression (\%), in total sample $(n=14.478)$ and by gender. 


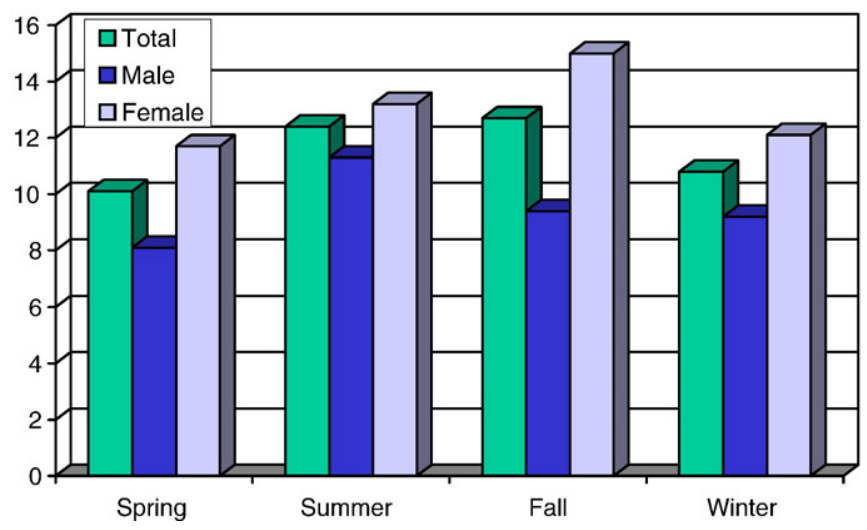

Fig. 2. Prevalence of sad mood (\%), in total sample $(n=14.478)$ and by gender.

on mood. No association was found between meteorological factors and mood status in these analyses.

\section{Discussion}

\subsection{Main findings}

The prevalence of major depression and sad mood varied over the seasons in our sample, with seasonal peaks in the summer and fall of 2006. Men had seasonal peaks of major depression and sad mood in the summer, while women had seasonal peaks in the fall.

We then examined the influence of daily weather conditions on the prevalence of major depression and sad mood in the general population, and found that there was no association between the weather and mood. Odds ratios for temperature, sunshine and rainfall as determinants of major depression or sad mood were all estimated at 1 , indicating no relation at all, with very small confidence intervals, indicating these estimates are very precise. In multiple regression models, the odds ratios for weather conditions remained unchanged, while the odds ratios for season indicating seasonal prevalence variation also remained intact, suggesting that none of the meteorological factors in this study is accountable for the seasonal variations in mood that were observed. Ancillary analyses proved these findings to be robust.

\subsection{Previous studies}

Although seasonal peaks reported in the literature differ, they are usually reported during winter (Harmatz et al., 2000; Magnusson, 2000; Morken et al., 2002; Murase et al., 1995; Nayyar and Cochrane, 1996; Oyane et al., 2008). We found seasonal peaks in the summer and fall, in accordance with a Japanese study from Ozaki et al. (1995) and a Norwegian study from Stordal et al. (2008). We also found different peaks for men and women, in accordance with an earlier study reporting gender differences in seasonal peaks of depression-related hospital

Table 2

Meteorological determinants of MDD in the general population $(n=14.478)$.

\begin{tabular}{|c|c|c|}
\hline & Univariate association & Multiple model \\
\hline & OR (95\% CI) & OR $(95 \% \mathrm{CI})$ \\
\hline Mean daily temperature & $1.00(1.00-1.00)$ & $1.00(0.99-1.00)$ \\
\hline Daily duration of sunshine & $1.00(0.99-1.00)$ & $1.00(0.99-1.00)$ \\
\hline Daily duration of rainfall & $0.99(0.99-1.00)$ & $0.99(0.99-1.00)$ \\
\hline \multicolumn{3}{|l|}{ Meteorological season } \\
\hline Summer vs. spring & $1.32(1.13-1.55)^{*}$ & $1.34(1.09-1.64)^{*}$ \\
\hline Fall vs. spring & $1.29(1.09-1.53)^{*}$ & $1.29(1.07-1.55)^{*}$ \\
\hline Winter vs. spring & $1.14(0.96-1.36)$ & $0.91(0.87-1.34)$ \\
\hline
\end{tabular}

Table 3

Meteorological determinants of sad mood in the general population $(n=14,478)$.

\begin{tabular}{|c|c|c|}
\hline & \multirow{2}{*}{$\frac{\text { Univariate association }}{\text { OR }(95 \% \mathrm{CI})}$} & \multirow{2}{*}{$\frac{\text { Multiple model }}{\text { OR }(95 \% \mathrm{CI})}$} \\
\hline & & \\
\hline Mean daily temperature & $1.00(1.00-1.01)$ & $1.00(0.99-1.00)$ \\
\hline Daily duration of sunshine & $1.00(0.99-1.00)$ & $0.99(0.99-1.00)$ \\
\hline Daily duration of rainfall & $0.99(0.99-1.00)$ & $0.99(0.99-1.00)$ \\
\hline \multicolumn{3}{|l|}{ Meteorological season } \\
\hline Summer vs. spring & $1.26(1.09-1.44)^{*}$ & $1.26(1.06-1.49)^{*}$ \\
\hline Sall vs. spring & $1.29(1.12-1.49)^{*}$ & $1.25(1.07-1.47)^{*}$ \\
\hline Winter $v$ s. spring & $1.07(0.93-1.25)$ & $1.03(0.87-1.22)$ \\
\hline
\end{tabular}

$* P$-value $<0.05$.

admission (Morken et al., 2002). What accounts for these reported differences in seasonal peaks of depression is still unknown.

Apart from a recent study in which high temperatures were found to be associated with an increase in suicide rates (Page et al., 2007), we know of no large-scale epidemiological studies that directly associate meteorological factors with mood problems. Molin et al. (1996) found a significant correlation between depression scores and sunshine, global radiation, length of daylight and temperature in SAD patients, while Albert and colleagues (Albert et al., 1991) found that almost 50\% of the SAD patients in their study showed an energyelevating effect of sunshine. It should be kept in mind however that SAD is a specifier within the depression spectrum that affects only a minority of the depressed patients (Magnusson and Partonen, 2005). Light deprivation is believed to be a causal factor in the development SAD, also supported by the effectiveness of light therapy in SAD (Westrin and Lam, 2007). Our findings suggest that such a meteorological influence is not likely with respect to 'regular' depression and mood in the general population, in keeping with the previous work of Watson (Watson, 2000).

\subsection{Methodological considerations}

Since this is a cross-sectional study using self-reported data, some caution is in place, especially when it comes to causal inferences. Ideally, one would need a large cohort that would be followed up frequently on their depression status to examine the association between weather conditions and mood. Instead, our participants responded at different time points over the course of 12 months, which enabled us to link depression status to the weather conditions on these time points. Our study also suffered from a low response rate, which may have introduced some form of selection bias. However, comparison of our sample's demographics with those of the base population showed that our sample appears to be representative for the general population. Furthermore, the large number of participants, the stability of the response rate across the seasons, and the clear seasonal variation we found in combination with the absence of an association with meteorological factors make it less likely that a higher response rate would have altered our results.

Furthermore, selection bias might be a problem in our sample when it comes to estimating the true prevalence of depression in our region, but it seems less likely to confound a supposed link between weather conditions and depressive symptoms. Hypothetically, it would be possible that mood mediates the effect of weather conditions on the response rate (a form of selection bias), but one would then expect an underestimation of the strength of the association, and not a complete absence of it, as we observe here.

Another issue pertains to the parameters for the supposed meteorological determinants in this study. It is unclear whether the (continued) exposure to temperature, sunshine and rainfall has an acute or time-delayed effect on mood, although an immediate effect seems most likely (Basu and Samet, 2002; Page et al., 2007). We addressed this by associating daily, monthly and quarterly means of our meteorological determinants to mood, and by investigating potential 
time lags between exposure to weather conditions and mood in retrospective analyses. None of these ancillary analyses yielded findings that differed from our main analyses, which adds to the robustness of our results.

Major strengths of this study are the large sample size and the use of a self-report measure (DID) that can classify according to the criteria for DSM-IV major depressive disorder, something that has hardly been done in large epidemiological studies. Collecting data using the Internet has many advantages, such as accessibility and absence of missing values, and there are sufficient indications that computerised and paper-and-pen questionnaires show similar construct validity (Butcher et al., 2000; Butcher et al., 2004). Balancing the strengths and limitations of this study, we feel our findings have a satisfactory validity base and can be generalized to other populations.

\section{Conclusion}

Despite the numerous references in everyday language suggesting that we way we feel is affected by the weather (e.g., 'sad weather', 'a sunny mood'), and contrary to popular belief, weather conditions and sad mood or depression do not seem to be associated. Future studies might use daily measures of well-being as outcome, since these might be more suitable for the immediate effects of weather conditions to emerge.

\section{References}

Albert, P.S., Rosen, L.N., Alexander Jr., J.R., Rosenthal, N.E., 1991. Effect of daily variation in weather and sleep on seasonal affective disorder. Psychiatry Research 36, 51-63. Basu, R., Samet, J.M., 2002. Relation between elevated ambient temperature and mortality: a review of the epidemiologic evidence. Epidemiological Review 24, 190-202.

Butcher, J.N., Perry, J.N., Atlis, M.M., 2000. Validity and utility of computer-based test interpretation. Psychological Assessment 12, 6-18.

Butcher, J.N., Perry, J., Hahn, J., 2004. Computers in clinical assessment: historical developments, present status, and future challenges. Journal of Clinical Psychology $60,331-345$.

de Graaf, R., van Dorsselaer, S., ten Have, M., Schoemaker, C., Vollebergh, W.A., 2005 Seasonal variations in mental disorders in the general population of a country with a maritime climate: findings from the Netherlands mental health survey and incidence study. American Journal of Epidemioliogy 162, 654-661.

Harmatz, M.G., Well, A.D., Overtree, C.E., Kawamura, K.Y., Rosal, M., Ockene, I.S., 2000 Seasonal variation of depression and other moods: a longitudinal approach. Journal of Biological Rhythms 15, 344-350.

Magnusson, A., 2000. An overview of epidemiological studies on seasonal affective disorder. Acta Psychiatrica Scandinavica 101, 176-184.

Magnusson, A., Partonen, T., 2005. The diagnosis, symptomatology, and epidemiology of seasonal affective disorder. CNS Spectrum 10, 625-634.

Molin, J., Mellerup, E., Bolwig, T., Scheike, T., Dam, H., 1996. The influence of climate on development of winter depression. Journal of Affective Disorders 37, 151-155.

Morken, G., Lilleeng, S., Linaker, O.M., 2002. Seasonal variation in suicides and in admissions to hospital for mania and depression. Journal of Affective Disorders 69, 39-45.

Murase, S., Kitabatake, M., Yamauchi, T., Mathe, A.A., 1995. Seasonal mood variation among Japanese residents of Stockholm. Acta Psychiatrica Scandinavica 92, 51-55.

Nayha, S., Vaisanen, E., Hassi, J., 1994. Season and mental illness in an Arctic area of northern Finland. Acta Psychiatrica Scandinavica. Supplementum 377, 46-49.

Nayyar, K., Cochrane, R., 1996. Seasonal changes in affective state measured prospectively and retrospectively. British Journal of Psychiatry 168, 627-632.

Oyane, N.M., Bjelland, I., Pallesen, S., Holsten, F., Bjorvatn, B., 2008. Seasonality is associated with anxiety and depression: the Hordaland health study. Journal of Affective Disorders 105, 147-155.

Ozaki, N., Ono, Y., Ito, A., Rosenthal, N.E., 1995. Prevalence of seasonal difficulties in mood and behavior among Japanese civil servants. American Journal of Psychiatry $152,1225-1227$.

Page, L.A., Hajat, S., Kovats, R.S., 2007. Relationship between daily suicide counts and temperature in England and Wales. British Journal of Psychiatry 191, 106-112.

Rosenthal, N.E., Sack, D.A., Gillin, J.C., Lewy, A.J., Goodwin, F.K., Davenport, Y., Mueller P.S., Newsome, D.A., Wehr, T.A., 1984. Seasonal affective disorder. A description of the syndrome and preliminary findings with light therapy. Archives of General Psychiatry 41, 72-80.

Sheeran, T., Zimmerman, M., 2002. Case identification of depression with self-report questionnaires. Psychiatry Research 109, 51-59.

Stordal, E., Morken, G., Mykletun, A., Neckelmann, D., Dahl, A.A., 2008. Monthly variation in prevalence rates of comorbid depression and anxiety in the genera population at 63-65 degrees North: the HUNT study. Journal of Affective Disorders $106,273-278$

Watson, D., 2000. Mood and temperament. The Guilford Press, New York.

Westrin, A., Lam, R.W., 2007. Seasonal affective disorder: a clinical update. Annals of Clinical Psychiatry 19, 239-246.

Zimmerman, M., Sheeran, T., Young, D., 2004. The diagnostic inventory for depression: a self-report scale to diagnose DSM-IV major depressive disorder. Clinical Psychology $60,87-110$.

Zimmerman, M., Chelminski, I., McGlinchey, J.B., Young, D., 2006. Diagnosing Major Depressive Disorder VI; performance of an objective test as a diagnostic criterion. Journal of Nervous and Mental Disease 194, 565-569. 